\title{
Christianity's Influence on Rational Choices and Irrational Choices of Its Believer During the COVID-19 Epidemic Period
}

\author{
Leyu Liu ${ }^{1, \dagger}$, Sihan Zan ${ }^{2, \dagger}$, Xin Zhang ${ }^{3, *, \dagger}$
}

\author{
${ }^{1}$ RDFZ Xishan School, Beijing, China \\ ${ }^{2}$ College of Communication, Boston University, Boston, USA \\ ${ }^{3}$ United World College, Changshu China \\ ${ }^{*}$ Corresponding author. Email: guanghua.ren@gecacademy.cn \\ These authors contributed equally.
}

\begin{abstract}
Over the past year, preventing covid-19 has become a part of all human life. Globally, as of 5:54 pm CEST, 27 July 2021, there have been 194,608,040 confirmed cases of COVID-19, including 4,170,155 deaths, reported to WHO. Covid-19 leads to many deaths, which is a great challenge for human medical technology, and it is also worth studying in the field of humanities. In an epidemic situation, people's decisions will be affected by their own cultural environment. This work aims to explore the impact of Christianity on human rational or irrational choices during covid-19. Here, we use the application of Rational Choice Theory (RCT) as the basis for our research, collected relevant information on major events related to Christianity during the period. In conclusion, the research shows that the judgment of rationality and irrationality of behavior should only be determined by the objective perspective and position of the judge. Christian culture is diverse, so it contributes to both rational and irrational choices.
\end{abstract}

Keywords: Christianity, COVID-19, Rational Choice, Irrational Choice

\section{INTRODUCTION}

\subsection{RATIOANLISM, IRRATIONALISM AND CHRISTIANITY}

Starting from December 2019, the COVID-19 pandemic has caused a global pandemic of respiratory illness. It has a quick-spreading through breaths, talks and sneezes, and has symptoms such as cough, fever, and loss of taste. The global epidemic has caused population loss and economic depression in most countries around the world. Until May 2021, the COVID-19 pandemic has caused over 170 million confirmed cases with over 3.54 million deaths [1]. Moreover, the IMF (International Monetary Fund) predicts that the global economy will contract by approximately $3.0 \%$ during the pandemic, and the last financial crisis caused a shrink of only $0.7 \%$ in 2009 . In 2021, the epidemic situation has been alleviated as the coronavirus vaccine has been popularized worldwide. Under the COVID period, Christain beliefs played a crucial role in guiding human rational and irrational actions such as governmental legislation, congregations, and religious support.

Speaking of identifying rational and irrational actions, it is important to first clarify the mode of actions. No matter how hard it is to differentiate between irrational and rational actions, it is clear that all modes are in the same structure. Actions are taken under motivations or enforcements, and every single step must be useful to reach the targeted goal. Under the topic of how Christianity impacts irrational and rational actions during the pandemic, Christian beliefs function as motivations or enforcements as a lighthouse to guide. All movements are impacted as well. For all taken actions, the only thing action takers (mostly Christians) did was follow what the beliefs were guiding them. Sometimes it leads to bad consequences, sometimes good ones. Once the actions were completed, the outside world would define the actions based on a comparatively logical and generally accepted way, satisfying the popular perceptions. The popular perception concerns more about the degree of social damage. From the previous section, the concepts of 
rationality and irrationality are summarized from the perspectives of philosophy, economics and Christianity beliefs. This part will introduce a more concrete definition based on the above theoretical definition of rationality and irrationality.

\subsection{The Origin of Rationalism and Irrationalism in the Field of Philosophy}

Since human beings began to study philosophy, rationalism and irrationalism have always been the two major themes of philosophers' thinking. From ancient Greek philosophy, the earliest period of philosophy, to German classical philosophy, the position of rationalism has been constantly promoted, and its theory has been gradually improved. The origin of all things has always been one of the main problems of ancient Greek philosophers. They took exploring the essence of things as their own responsibility and gave their own interpretation of the composition of the world in an era of underdeveloped science. Thales is the first philosopher in the history of western philosophy. Doubts have always existed about whether Thales wrote anything. Aristotle, widely considered the peak of Greek Philosophy by later scholars, organized Thales' philosophy. When Aristotle reported Thales's pronouncement that the primary principle is water, he made a precise statement: 'Thales says that it [the nature of things] is water' (Metaph. 983 b20). In conclusion, Thales says water is the primary principle [2]. This is undoubtedly a statement of rationalism because, in this sentence, he admits that there is a primary principle. The rationalism that we are talking about today is generally believed to come from Descartes's philosophy. The rationalists represented by Descartes believe that human reasoning can be used as the theoretical basis of the source of knowledge, which is consistent with Thales' philosophical method. Aristotle himself also appreciated rationalism. He said, "the activity of philosophical wisdom is just recognized as the happiest of all virtuous activities", "for people, life in line with reason is the best and happiest because reason is more human than anything else." Rationalism is also the foundation of modern philosophy. Hegel, the famous German philosopher, is the representative of rationalism. His whole philosophical system describes the development process of rationality. He said, "besides rationality, there is nothing realistic. Rationality is absolute power." However, Believers of irrationalism prefer to emphasize instinctive response, emotion and will than rational choice. More and more research on psychology from the late 19th century to the beginning of the 20th century has contributed a lot to the development of irrationalism. Schopenhauer is a representative of irrationalism, and his views interpret irrationalism to a certain extent. In the 19th century, rationalism was the mainstream voice, and Schopenhauer took a clear stand against Hegel and his rationalism at that time [3]. Schopenhauer believes that all rationalist theories must be based on an "absolute" that is not subject to any conditions. He and other believers of irrationalism do not recognize the existence of this above all "absolute". At the same time, for irrationalists, morality and rationality are contradictory concepts. Irrationalists are often worried about extreme rationalism, and they believe that such artificial "rationality" may endanger human freedom. Schopenhauer said: "The majority of men... are not capable of thinking, but only of believing, and... are not accessible to reason, but only to authority."

\subsection{The Definition of Rationality and Irrationality in the Economics Field}

However, rationality and irrationality discussed in this paper are not two philosophical methods. In philosophy, rationality and irrationality have complicated relations under different backgrounds. Rationalism itself is divided into many schools, and the opponents of rationalism come from a different perspective. It is difficult to discuss a practical problem within such a large philosophical framework. Therefore, the rationality and irrationality discussed in this paper are more inclined to the definition of rationality in classical economics. According to Wade Hands' book Philosophy and Economics, the traditional relationship between philosophy of science and economics has been that philosophy comes first (laying the foundations for knowledge). The economic methodology then translates those philosophical ideas into the context of economic science [4]. The essential interdependency of philosophical and economic ideas was a prominent feature of classical economics. Adam Smith was the author of The Theory of Moral Sentiments as well as Wealth of Nations. John Stuart Mill was an extremely wide-ranging scholar, as well known as the author of A System of Logic as of The Principles of Political Economy. And of course, Karl Marx's Capital also drew on intellectual resources from economics, philosophy and a number of other fields. Classical political economy was deeply influenced by philosophy different philosophies for different economists but influenced nonetheless - and ideas also flowed freely in the opposite direction, from political economy to various areas of philosophical inquiry [5]. The famous economist Adam Smith gave his definition of rational choice. Adam Smith believes that man's rationality lies in his choice of the best interests of himself in the comparison of various interests and his satisfaction of his greatest needs with the least sacrifice. The mainstream of modern western economics generally believes that rational choice theory states that individuals use rational calculations to make rational choices and achieve outcomes aligned with their own personal objectives. These results are also associated with maximizing an individual's self-interest. Using rational choice theory is expected to result in outcomes 
that provide people with the greatest benefit and satisfaction, given the limited option they have available [6]. Adam Smith is not only an economist but also a moralist. Reason represents not only more wealth but also selfishness. He mentioned in another book, Theory of Moral Sentiments, that irrationalism could sometimes make society better. Irrational behavior can make people return wealth to the market and society, and it is not rational but moral that makes people donate money to charities and the poor [7].

\subsection{The Embodiment of Rational and Irrational Thoughts in Christian Culture}

Modern politicians believe that there are two forms of wisdom in western culture. One is called "Greek wisdom", the other is called "Jerusalem wisdom". Greek wisdom refers to rational wisdom, people's understanding of science, and the choice of interests. "Wisdom of Jerusalem" is closely related to religion, representing Christian values and the pursuit of Christian morality. The behavior of Christianity in actual historical events often shows the contradiction between rationality and irrationality, which comes from the polysemy and universality of Christianity's own doctrines. Therefore, here we will sort out some viewpoints in Christian philosophy and theology and discuss the rationality and irrationality in Christianity. Steven Weinberg, a famous Jewish physicist and Nobel laureate, said: "With or without religion, good people can have well, and bad people can do evil; but for good people to do evil, that takes religion." As a physicist, his views on religion are correct and widely accepted [8]. In fact, it has been proved that Christianity, as the religion with the largest number of believers in the world, has innumerable irrational blemishes in its glorious history. The idea of homomorphic Revenge (Latin: Lex talionis) frequently appears in the Hebrew Bible, which is the so-called Old Testament in Christianity. This kind of revenge means that the injured should treat the injured with the same harm. In Deuteronomy, especially in Chapter 13, The suspected massacre was described as such, "That prophet or dreamer must be put to death for inciting rebellion against the LORD your God... because you obey the LORD your God by keeping all his commands that I am giving you today and doing what is right in his eyes." (New International Version, 2011, Deuteronomy. 13:5-18) [9]. This makes many scholars believe that this kind of indiscriminate killing is genocide. At the end of the 11th century, the Crusade launched by the Catholic Pope caused great damage to the Middle East and Europe for 200 years. There is no doubt that these behaviors are irrational. Christian theologian Hans Küng believes that the conflict and contradiction between belief and reason can be traced back to Christian belief and Aristotle's philosophy. They are always in tension because belief needs to be demonstrated by reason, but it cannot be determined by reason, and it must be ensured that belief is firmer than reason [10]. The tension and contradiction between the two are inevitable. Wolfhart Pannenberg, another theologian, further pointed out that the reason why the relationship between belief and reason has puzzled Christian theologians from the beginning lies in the differences and contradictions between Hebrew religious tradition and ancient Greek philosophical tradition which are the two sources of the whole western culture. He believed that ancient Greek philosophers were only discussing some problems of causality and inevitability. However, the Christian philosophy of Augustine starts from the belief in Christian salvation and expresses a kind of new consciousness about human existence [11]. However, it is inappropriate to attribute Christianity and its philosophy to rationalism or irrationalism. Descartes himself is a devout Christian. He tried to use rationalism to explain the existence of God [12]. Calvin, another representative of Christian philosophy, believes that because humans are defiled by sin, a human cannot know God by reason [13]. The Bible also has some content that advocates rationalism, as it claims, "Let everyone be subject to the governing authorities, for there is no authority except that which God has established. God has established the authorities that exist. Consequently, whoever rebels against the authority is rebelling against what God has instituted, and those who do so will bring judgment on themselves." (New International Version, 2011, Romans. $13: 1-2)[14]$

\subsection{The Conclusion of Background Research}

In general, rationality and irrationality are dialectical thinking that cannot be bypassed in philosophy and economics, and Christianity has pushed this concept. We hope to define rational and irrational behaviors of Christians during the COVID-19 pandemic.

\section{RATIONAL AND IRRATIONAL ACTIONS ON THE LEVEL OF GOVERNMENT, BIG INSTITUTIONS, AND INDIVIDUALS}

\subsection{Irrational Cases}

Digging into the so-called irrational actions, christians tend to ignore the popular perceptions because they are blurred by their beliefs. Under such a situation, actions that seem reasonable to christian believers may cause huge social damage and will be defined as irrational actions under the popular perception scales. At the governmental level, the siege of Congress best proves how Christianity results in irrational actions. Over the years, belief in white supremacy seeped into the church.

According to Kerry Wallace, a religious politist, the 
siege of Congress was a logical necessity for white American Christians. Christianity has justified the enslavement of Africans and indigenous people for decades (Elmenshawy 1). At this point, the Christian groups have ignored the community's safety and fairness between all races [15].

Moving forward to a narrower level, big institutions, such as the Christian group, had much impact by their religious convictions as well. Before the COVID-19, the Christian members followed what the bible tells to gather regularly. From Hebrews 10:24-25, the bible states, "Let us consider how we may spur one another on toward love and good deeds, not giving up meeting together, as some are in the habit of doing, but encouraging one another-and all the more as you see the Day approaching." However, due to the rapid spread of coronavirus, gatherings are strictly prohibited because it violates the social distancing policies. Encouraged by verses and references from the bible, some Christian members still gathered in person during the pandemic. Other than encouraging people to gather, Christian beliefs also hold believers back by providing the sense of God's protection. From Psalm 91:6, King James Bible, it claimed: "Nor for the pestilence that walketh in darkness; nor for the destruction that wasteth at noonday." Even more, some Christians considered the coronavirus as God's revenge for the sins people have done. Holding the belief that gathering shows loyalty, not showing up during the pandemic represents a worse sin. However, while taking action of gathering in person, Christian members lost sight of safety issues. Consequently, gathering causes more infection cases, which is considered harmful and selfish by the public. While it is reasonable for believers to gather during the covid period, it does not make sense to non-Christians.

For individuals, Christianity beliefs play an important role against mask policy. Some of the anti-maskers believe that being forced to wear a face-covering violates their religious rights. Specifically, covering one's face represents dishonors to God. Others refused to wear masks because of the political party they stood for. More Christian people refused to wear masks after former president Donald Trump announced he is against mask wearing. Christians rather take the risk to get infected but refuse to challenge their beliefs. To make matters worse, anti-maskers are not satisfied with protesting by themselves. They even lead protests against people who wear masks. There were a lot of protests, mask-burnings, and killings going on in the USA. The public considers those actions are considered selfish and crazy by the public, who do not share the same idea that mask-wearing is insulting.

In conclusion, actions were differentiated by their degree of social damage on the popular perception scale, but not a customized scale that suits each population.

\subsection{Rational Cases}

In the opposite situation, actions that suit the Christian logic and bring no damage to the public are considered rational actions on the popular perception scale. Some governmental policies were made based on the Christian conceptions that all lives matter and neighbours always matter more than individuals themselves. For example, the "social distancing" policy has always been the core principle for any policy response to the coronavirus. The "social distancing" policy has improved the epidemic by segregating people and reducing the frequency of private gatherings.

Almost all public places strictly follow the "social distancing" policy, especially restaurants, schools, and offices [1]. All other available places, including a lot of churches, have been voluntarily offering free testing and vaccines to the public. These actions were highly praised by the public because the beliefs Christians followed at this point fit the popular perceptions, which lead to good consequences for the public and are understandable. For individuals, beliefs held their back during the pandemic and healed them. According to Pew Research Center's latest report, nearly 3 in 10 Americans say that their religiosity has increased since the pandemic began and that they believe the same is true of their countrymen. As the uncertainty of the COVID-19 pandemic continues to grow, people with religious backgrounds would turn to their faith for comfort and solace during this painful time [16].

As the fact shows, the only way to distinguish irrational actions from rational rations is by an outsider's definition, according to the popular perception that focuses on the degree of social damage. The definitions of rationality and irrationality seem reasonable to different targeted audiences, depending on the purpose of their actions and the framework by which they are defined. This relativistic logical conflict is not absolute but flexible. Is it possible to redefine rational and irrational actions? What scale could the redefinition be based on? In the following articles, rational and irrational behavior will be redefined.

\section{CONCLUSION}

The Covid-19 caused significant damage not only to people's physical health but also to mental fitness. During this epidemic, people constantly lose the bondage of reason and become irrational and driven by their own emotions and desires. Nevertheless, it is incorrect to discuss these two concepts without critical thinking because "rationality" and "irrationality" are relative concepts, especially when a religious group of people are discussed in this condition because the religious stories more influence them. 
Firstly, it is not objective and fair to directly judge the behavior under the epidemic as purely rational or purely irrational because the basic premise of the religious and non-religious judgment of their own behaviors is contradictory. The direct contradiction lies in that the criterion of non-believers' behaviors comes from the real interests of the government, the collective and the individual. In contrast, the criterion of believers' behaviors comes from the supreme purview of God and his represented soul mystery and intuition. In this way, it is unreasonable to judge whether a behaviors under the pandemic is rational or not because the concept of "rationality" is relatively according to Thomas Kuhn, a famous philosopher. He believes that rationality is like science, relative in different cultural contexts. In this case, we cannot easily define rational and irrational behaviors so directly and absolutely. From the perspective of society and the public, the Christian demonstration in South Korea this time is irrational because they did not show their flexibility and bending as a person in the face of the sudden outbreak of the epidemic, but rigidly abide by the doctrine of Christianity. The irrationality of the Christians illustrates that they ignored the government's request for quarantine and held a mass rally, which led to another outbreak of the epidemic. Moreover, the source of such irrational behaviors points to the cultural background of the parade - Christianity. From the perspective of Christians, they probably did not regard their actions as irrational. This is mainly reflected in their perception of authority between them, and the ordinary people are different. For the public, government and policies act as authoritative organizations and guide the development of society. In the perspective of Christians, God and the Bible are the creators of the world and human beings. As authoritative organizations, they are higher than the government, policies, and even everything else in the hearts of Christians. In the eyes of these fanatical Christians, the parade they held was a symbol and embodiment of reason and one of the crucial marks that separated them from the familiar people. Therefore, when two authoritative organizations and institutions advocate for the spirit and action of people in two different directions, conflict occurs. Therefore, I think we cannot take rationality and irrationality as absolute criteria to consider but should take them as a relative description to evaluate. When we look at this case from a more comprehensive and objective perspective, we can find that it is also irrational for some people to point the source of contradictions to the religion itself rather than the inflexible believers. Hence, we cannot take rationality and irrationality as an absolute standard to consider but should take them as a relative description to evaluate. Also, we can find that it is also irrational for some people to point the source of contradictions to the religion itself rather than the inflexible believers. When we take rationality as an absolute standard to measure the right or wrong of a thing, we can always find that the two always coexist. Taking a fresh look at this case and the more significant issue of rationality, we can take a more comprehensive look at the flexibility of the word rationality.

Secondly, it is worth mentioning that Christian behaviors are always rational in the definition of its believers and theologians, who also claim that God glorifies Christians through reason. However, contrary to the public perception, no matter what mysterious force the reason they preach comes from, the more fiercely they preach the reason, the more the public can perceive the underlying irrational force. Thus, religion can essentially change one's mind, so their decision making under the pandemic may be carried with huge pressure, which will drive them to be irrational. With the progress of human society, a person's religious belief has gradually become an important identity and label of a person. It has gradually reached an equal position with some innate characteristics, such as gender, age, etc. The significance of religion can be perfectly demonstrated by a famous ancient philosopher St. Augustin. As a devoted Christian, he explores how to reach eternal ethical life after heaven. Those who first accepted and supported Christianity were the poorest category because they were guaranteed to rise to heaven after suffering for a lifetime of pain. St. Augustine argued that the goal of studying rationality is not to bring wisdom, as Plato had said, but to bring the beauty of the divine state to its people. Moreover, St. Augustine is a Neo-Platonist. He claims that rationality is a gift from God. Humans have rationality, and our ability to make decisions is a gift from God. We have free will. Human nature is also sinful. He argues that because God is omnipotent, omniscient, therefore God cannot let evil happen; it is rather the free will of human beings, after making decisions, who brings evil and crime to this mortal world. It can be seen from some of his philosophical theories that religion is extremely terrible to the cognitive shaping of a person. It can make any thought of a person based on God. Therefore, our evaluation and judgment of religion in the paper may also be an underestimate and blasphemy of the power of religion to shape others, and it can even be irrational behavior. The power of religion was also demonstrated during the pandemic. To compare with health and social order, people who were holding the pride care more about freedom and God's will.

\section{REFERENCES}

[1] David Lawder. "Global economy in 2020 on track for sharpest downturn since 1930s: "IMF". April 14, 2020. Reuters. https://www.reuters.com/article/us-imf-worldbankoutlook-idUSKCN21W1MA

[2] Internet encyclopedia of philosophy. (n.d.). Retrieved September 26, 2021, from https://iep.utm.edu/thales/. 
[3] Schopenhauer, A. (1990). On the fourfold root of the principle of sufficient reason. Open Court.

[4] Hands D.W. (2008) Philosophy and Economics. In: Palgrave Macmillan (eds) The New Palgrave

[5] Dictionary of Economics. Palgrave Macmillan, London. https://doi.org/10.1057/978-1-349-95121-5_1622-2

[6] APA. (n.d.). Apa dictionary of psychology. American Psychological Association. Retrieved September 26, 2021, from https://dictionary.apa.org/rational-economic-man

[7] Smith, A., \& Marijs, A. J. (2018). Theorie Van De Morele gevoelens. A\&W Uitgeverij.

[8] Weinberg, S. (1999, April). A Designer Universe? A designer universe? Retrieved September 26, 2021, from https://www.physlink.com/Education/essay_weinbe rg.cfm.

[9] Holy bible: New international version. (2011). NIV Online. https://www.biblestudytools.com/niv/

[10] Kung, H. (2008). Beginning of all things - science and religion. William B Eerdmans Publishing.
[11] Pannenberg, W. (1996). Theologie und Philosophie: Ihr VERHÄLTNIS Im Lichte Ihrer gemeinsamen geschichte. Vandenhoeck \&amp; Ruprecht.

[12] Descartes, R. (2018). Meditations on first philosophy. SMK Books.

[13] Parker, T. H. L. (2002). Calvin: An introduction to his thought. Continuum.

[14] Holy bible: New international version. (2011). NIV Online. https://www.biblestudytools.com/niv/

[15] Mohamed Elmenshawy. "Vote for Trump and siege Congress, what do American Christians and white extremist groups have in common?". January 1st, 2021. Al Jazeera. https://chinese.aljazeera.net/news

[16] Mya Jaradat. "America's unique religious response to the COVID-19 pandemic". January 27th, 2021. Deseret

News. https://www.deseret.com/indepth/2021/1/27/22250 317/americans-faith-growing-during-pand emic-more-than-any-western-country-covid-19-mo re-religious 